\title{
The Effects of Cigarette Smoking on Serum Carboxyhemoglobin and Calcium Levels in Apparently Healthy Male Smokers in Benin City, Nigeria
}

\author{
Grace Umahi-Ottah ${ }^{1}$, Babatunde Ishola Gabriel Adejumo ${ }^{2 *} \mathbb{C}^{\text {, Elvis Osamede Godwins }}{ }^{2}$, \\ Uchechukwu Dimkpa ${ }^{3}$, Simon Uzor ${ }^{4}$, Usman Itakure Abdulkadir ${ }^{5}$, \\ Oladimeji Nasiru Abdulrahman6, Noreen Ebelechukwu Agbapuonwu', \\ Onochie Anslem Ajugwo ${ }^{8}$, Musiliu Adewale Oyenike ${ }^{9}$
}

${ }^{1}$ Department of Physiology, Ebonyi State University, Abakaliki, Nigeria; ${ }^{2}$ Department of Medical Laboratory Science, University of Benin, Benin City, Nigeria; ${ }^{3}$ Department of Physiology, Nnewi Campus, Nnamdi Azikiwe University, Awka, Nigeria; ${ }^{4}$ Department of Applied Science, Faculty of Health and Applied Sciences, University of West of England, Bristol, UK; ${ }^{5}$ Department of Medical Laboratory Science, College of Health Sciences and Technology, Markafi, Nigeria; ${ }^{6}$ Department of Medical Laboratory Science, College of Health Technology, Offa, Nigeria; ${ }^{7}$ Department of Nursing, Nnamdi Azikwe University, Akwa, Nigeria; ${ }^{8}$ Department of Medical Laboratory Science, Madonna University, Elele, Nigeria; ${ }^{9}$ Department of Medical Laboratory Science, College of Health Sciences, Ladoke Akintola University of Technology, Ogbomoso, Nigeria

Correspondence to: Adejumo Babatunde Ishola Gabriel, babatunde.adejumo@uniben.edu; bigadejumo@yahoo.com Keywords: Carboxyhaemoglobin, Calcium, Smokers, Nonsmokers, Benin City Received: November 3, $2021 \quad$ Accepted: January 11, $2022 \quad$ Published: January 14, 2022

Copyright $\odot 2022$ by author(s) and Scientific Research Publishing Inc.

This work is licensed under the Creative Commons Attribution International License (CC BY 4.0). http://creativecommons.org/licenses/by/4.0/

\section{(c) (1) Open Access}

\section{ABSTRACT}

The aim of this study is to determine the effects of cigarette smoking on carboxylhaemoglobin $(\mathrm{COHb})$ and calcium levels in apparently healthy male cigarette smokers in Benin City, Nigeria. Thirty active cigarette smokers and thirty healthy, non-smokers within the same age range participated in this study. Serum $\mathrm{COHb}$ level was estimated using ELISA reagent from Calbiotech, USA, while calcium concentration was estimated spectrophotometrically with commercially purchased kit from Randox, UK. Results showed higher concentration of $\mathrm{COHb}$ but lower concentration of calcium level among the cigarette smokers when compared with the non-smokers. There were no statistically significant differences observed in $\mathrm{COHb}$ levels between smokers with regard to smoking duration ( $<5$ yrs vs. $\geq 5 \mathrm{yrs} ; \mathrm{p}=0.893$ ) and number of sticks of cigarette per day ( $<5$ sticks/day vs. $\geq 5$ sticks/day; $p=0.256$ ). In contrast, significantly higher mean $\mathrm{COHb}$ level was found in subjects who smoked "always" compared with those who smoked "occasionally" ( $p=0.04)$ and those who smoked "rarely" 
$(p=0.006)$. On the other hand, the smokers' serum calcium level was not affected by smoking duration, frequency and number of sticks consumed. In conclusion, the present study confirms that cigarette smoking contributes to abnormally high COHb levels, which is associated with adverse health consequences from carbon-monoxide poisoning in the body. In addition, cigarette smoking may interfere with the mechanisms responsible for the absorption of calcium in the gastro-intestinal tract, thus leading to poor absorption as well as low levels of calcium in the body.

\section{INTRODUCTION}

Carbon monoxide (CO) is a colourless and odourless toxic gas that is produced by the incomplete combustion of carbon-containing materials [1]. Important sources of $\mathrm{CO}$ include tobacco, oil, natural gas, petrol, diesel, wood, and coal [2]. Carbon monoxide's affinity for haemoglobin has been put at over 245 times when compared with oxygen, so CO displaces oxygen and binds with haemoglobin in red cells to produce carboxyhaemoglobin $(\mathrm{COHb})$. Carboxyhaemoglobin therefore acts as a sensitive and specific marker of atmospheric CO exposure from both indoor and outdoor sources [3]. There has been increasing concern that prolonged exposure to low levels of CO may have adverse health effects, particularly cardiovascular and neurophysiological [4]. Diminished exercise tolerance has been reported as one of the adverse cardiovascular consequences of $\mathrm{CO}$ at $\mathrm{COHb}$ levels of $2 \%-5 \%$, both in those with ischaemic heart disease $[5,6]$ and in healthy individuals [7]. Chronic $\mathrm{CO}$ exposure may also increase the risk of developing heart failure, even in ambient air pollution $[8,9]$. Furthermore, it has been reported that elevated levels of CO may contribute to the development of coronary heart disease $[10,11]$.

Calcium is a very essential mineral or element that plays a very important role in the physiological and biochemical processes of organisms and cells [12]. The calcium ion functions as an electrolyte and plays a vital role in the maintenance of normal functioning of the circulatory, muscular, and digestive systems $[12,13]$. Calcium is also very important in bone formation and supports the synthesis and functions of blood cells. For example, it regulates the contraction of muscles and nerve conduction, by acting as a second messenger in signal transduction pathways, in neurotransmitter release from neurons and in contraction of all muscle cell types. It also serves as a cofactor in many enzymes and involves in regulation of fertilization process, heart rate, blood pressure and clotting of blood [12,13]. In addition, the maintenance of the potential difference across excitable cell membranes and protein synthesis are other very important functions of calcium ions in the body [12,13]. Calcium deficiency results in hypocalcemia, often caused also by inadequate secretion of parathyroid hormone or defective PTH receptors in cells [14]. Symptoms include neuromuscular excitability, which potentially causes tetany and disruption of conductivity in cardiac tissue [15], which may be linked to heart failure, low blood pressure (hypotension) and life threatening rhythm disorders of the heart [16].

Cigarette smoking affects nearly all the organs in the body thus causing many diseases among the smokers which reduce their health and quality of life [17]. There are clear evidences which demonstrate tobacco smoking as a major cause of premature death, cancer, and a variety of chronic diseases, such as coronary heart disease and chronic obstructive pulmonary disease [18, 19]. There are also evidences to show that cigarette smoking is a risk factor for fatigue and poor physical fitness in men [20, 21]. Cigarette smoke contains more than 7000 chemicals [22]. Inhaling cigarette smoke exposes the cigarette smoker to these numerous toxins. Exposure to this complex chemical mixture causes immediate adverse physiologic effects shortly after the exposure occurs [22].

Studies have suggested that cigarette smoke contributes immensely to $\mathrm{CO}$ exposure, hence increased blood $\mathrm{COHb}$ levels especially among smokers [2]. Similarly, studies have shown that cigarette smoking decreases the absorption of vitamin $\mathrm{D}$ and calcium from the diet, leading to lower bone density and weaker bones [23]. Although there is an extensive literature on the effects of cigarette smoking on car- 
bon-monoxide poisoning and its associated adverse effects, information on the underlying mechanisms is limited in the Nigerian population. Similarly, several studies have identified cigarette use as a risk factor for low bone mineral density and osteoporotic fracture. However, the biological mechanisms by which smoking or components of cigarette smoke, influence bone mineral density and bone loss, are not well understood. There is also paucity of studies assessing the serum $\mathrm{COHb}$ and calcium levels in the Nigerian male smokers. In this study therefore, we assessed the serum level of these biochemical substances and possible factors that may influence their concentrations since these parameters are affected by chronic exposure to cigarette smoke and have also been implicated as risks for certain adverse health consequences.

\section{METHODOLOGY}

\subsection{Study Design}

This study is a cross-sectional study involving a total of sixty males (30 active smokers; 30 non smokers) within the ages of 20 - 41 years who volunteered to participate in the study. Individuals with a history of cigarette smoking (daily or occasionally) for at least one year were considered as active smokers and were selected from various motor parks in Benin City. The control group (non-smokers) comprises of healthy young men of same age range, who at the time of the study does not smoke at all. Ex-smokers or past smokers as well as female smokers were excluded from the study. Unhealthy adults with a history of any acute or chronic illness, bleeding disorder or drug addiction were also excluded from the study. The personal consents of individual participants were sought and obtained after explaining the purpose of the research. A structured questionnaire was administered to every participant before his participation in the study.

\subsection{Questionnaire/Ethical Approval}

Questionnaire consisted of questions designed to elicit details about their personal data, residence, surrounding environment, medications, history of underlying diseases and smoking history (smoking duration, frequency, number of sticks consumed per day, control of smoking habit, family history of smoking and awareness of risk of smoking). The Ethical committee of Ministry of Health, Edo State and leaders of the various motor parks approved this study. The ethical committee's approval number is HA 737/85.

\subsection{Blood Collection and Analysis}

Five millilitres of fasting blood was collected and dispensed into a plain container. The non anticoagulated blood was allowed to clot, spun at $1500 \mathrm{rpm}$ for 10 minutes and the supernatant serum was separated into a separate sterile tubes. The serum was stored at $-20^{\circ} \mathrm{C}$ for up to 2 weeks prior to analysis. Analysis for carboxylhaemoglobin was done using commercially purchased ELISA kit from Calibiotech U.S.A. while, serum calcium level was determined using reagent from Randox UK.

\subsection{Data Analysis}

Descriptive data was expressed as mean \pm standard deviation for continuous data and percentages for categorical variables. Comparative analysis between variables was done using independent sample t-test. Correlation tests involving two variables were done using the Pearson's bivariate correlation test. Test of significance was set at $\mathrm{p}<0.05$. All statistics were done using SPSS/IBM Software (version 20).

\section{RESULTS}

Table 1 shows the demographics, lifestyles and clinical characteristics of the study population. A total of 60 subjects were recruited for this study including 30 non-smoking non smokers, and 30 active smokers. The mean age of the participants was 35.53 years (ranged from 20 to 78 years) with a SD of \pm 14.67 years. Majority of the control group (30\%) and smokers (63.3\%) were of age group 20 - 29 yrs. Most (63.3\%) of 
Table 1. Selected demographic and smoking characteristics of the study population.

\begin{tabular}{lccc}
\hline \multicolumn{1}{c}{ Characteristics } & $\begin{array}{c}\text { Non smokers }(\mathrm{n}=30) \\
\text { Mean } \pm \text { SD or } \\
\mathrm{n}(\%)\end{array}$ & $\begin{array}{c}\text { Smokers }(\mathrm{n}=30) \\
\text { Mean } \pm \text { SD or } \\
\mathrm{n}(\%)\end{array}$ & $\begin{array}{c}\text { Total }(\mathrm{n}=60) \\
\text { Mean } \pm \text { SD or } \\
\mathrm{n}(\%)\end{array}$ \\
\hline $\begin{array}{l}\text { Age (years) } \\
20-29\end{array}$ & $43.26 \pm 17.02$ & $27.80 \pm 4.96^{*}$ & $35.53 \pm 14.67$ \\
$30-39$ & $9(30.0)$ & $19(63.3)$ & $28(46.7)$ \\
$\geq 40$ & $3(10.0)$ & $10(33.3)$ & $13(21.7)$ \\
Marital Status & $18(60.0)$ & $1(3.3)$ & $19(31.6)$ \\
$\quad$ Single & & & \\
Married & $11(36.7)$ & $25(83.3)$ & $36(60.0)$ \\
Family History of Smoking & $19(63.3)$ & $5(16.7)$ & $24(40.0)$ \\
$\quad$ No & & & \\
Yes & $19(63.3)$ & $10(33.3)$ & $29(48.3)$ \\
Awareness of Dangers of Smoking & $11(36.7)$ & $20(66.7)$ & $31(51.7)$ \\
$\quad$ No & & & $5(8.3)$ \\
Yes & $5(16.7)$ & $0(0)$ & $55(91.7)$ \\
\hline
\end{tabular}

${ }^{\star}$ Significant difference, $\mathrm{P}<0.001$.

the control subjects were married and majority $(83.3 \%)$ of the smokers were single. Majority of the participants (control, 63.3\%) had no family history of smoking, while $66.7 \%$ of the smokers had family history of smoking. Furthermore, a greater percentage of the non smokers $(83.3 \%)$ were aware of the dangers of smoking, while $100 \%$ of the smokers were aware of dangers of smoking.

Table 2 shows the mean, \pm SD, of the carboxyhemoglobin and calcium concentrations in the study population. Data shows a mean COHb level of $15.83 \%$ (SD, 8.53\%) for the smokers and 7.19\% (2.65\%) for non smokers. However, the mean $\mathrm{COHb}$ level was significantly greater $(\mathrm{p}<0.001)$ among smokers compared with the non smokers. The mean calcium concentration in both the smokers $(7.32 \pm 0.74 \mathrm{mg} / \mathrm{dl})$ and their non smokers $(9.68 \pm 1.08 \mathrm{mg} / \mathrm{dl})$ indicated values within the normal healthy range $(8.10-10.4$ $\mathrm{mg} / \mathrm{dl})$. However, the smokers indicated mean calcium levels significantly lower $(\mathrm{p}<0.001)$ compared with the non-smoking non smokers.

Pearson's bivariate correlation test indicated that there was a significant negative correlation $(\mathrm{r}=$ $-0.511 ; \mathrm{p}<0.001$ ) between the calcium concentration and $\mathrm{COHb}$ levels in the study population (Figure 1). This shows that serum calcium concentration increased with decreased in carboxy-hemoglobin levels.

Table 3 shows the smoking characteristics of the active smokers. Data shows that the mean $( \pm \mathrm{SD})$ duration of the smoking habit of the smokers was $3.86 \pm 2.41$ years. Majority of the smokers (70\%) had been in this habit for $<5$ years, while $30 \%(n=9)$ had been smoking for more than 5 years. A greater percentage $(50 \%)$ of the smokers indicated that they smoke "occasionally" while $36.7 \%$ reported that they smoke "often" and $13.3 \%$ said they smoke always. Data also indicated that the smokers took an average of 2.10 (SD, 1.18) sticks of cigarette per day. A greater percentage (93.3\%) smoked $<5$ sticks per day, while $6.7 \%$ reported that they smoked $\geq 5$ sticks per day. Majority of the smokers (86.7\%) indicated that they can stay without smoking, while $13.3 \%(\mathrm{n}=4)$ reported they cannot stay without smoking.

Table 4 shows the serum $\mathrm{COHb}$ levels of active smoking adults according to smoking duration, frequency, intensity and control of smoking habit. Independent sample t-test indicated no significant differences in serum $\mathrm{COHb}$ level between subjects whose smoking habit have lasted for $<5$ years and those that 
Table 2. Mean serum carboxy-hemoglobin and calcium levels among the study population.

\begin{tabular}{ccccc}
\hline Variables & Non-Smokers & Smokers & t-Statistics & P-Values \\
\hline Carboxy-hemoglobin (\%) & $7.19 \pm 2.65$ & $15.83 \pm 8.53$ & -5.29 & $<0.001$ \\
Calcium $(\mathrm{mg} / \mathrm{dl})$ & $9.68 \pm 1.08$ & $7.32 \pm 0.74$ & 9.83 & $<0.001$ \\
\hline
\end{tabular}

Table 3. Smoking characteristics of the active smokers.

\begin{tabular}{lc}
\hline \multicolumn{1}{c}{ Characteristics } & Mean \pm SD or N (\%) \\
\hline Duration of Smoking Habit (years) & $3.86 \pm 2.41$ \\
$<5$ years & $21(70 \%)$ \\
$\geq 5$ years & $9(30 \%)$ \\
Frequency of Smoking & \\
Always & $4(13.3 \%)$ \\
Often & $11(36.7 \%)$ \\
Occasionally & $15(50.0 \%)$ \\
Smoking Intensity (sticks per day) & $2.10 \pm 1.18$ \\
$<5$ & $28(93.3 \%)$ \\
$\geq 5$ & $2(6.7 \%)$ \\
Control Over Smoking Habit & \\
Yes & \\
No & $26(86.7 \%)$ \\
\hline
\end{tabular}

Table 4. Serum carboxyhemoglobin levels of active smoking adults according to smoking duration, frequency and intensity.

\begin{tabular}{|c|c|c|c|c|}
\hline \multirow{2}{*}{ Characteristics } & \multirow{2}{*}{$\mathrm{N}$} & \multirow{2}{*}{$\begin{array}{l}\mathrm{COHb}(\%) \\
\text { Mean } \pm \text { SD }\end{array}$} & \multicolumn{2}{|c|}{ Statistics } \\
\hline & & & Coefficient & P-Value \\
\hline \multicolumn{5}{|l|}{ Duration of Smoking Habit } \\
\hline$<5$ years & 21 & $15.69 \pm 8.43$ & $\mathrm{t}, 0.136$ & 0.893 \\
\hline$\geq 5$ years & 9 & $16.16 \pm 9.27$ & & \\
\hline \multicolumn{5}{|l|}{ Frequency of Smoking } \\
\hline Always & 4 & $27.10 \pm 3.21$ & \multirow{3}{*}{$\mathrm{F}, 5.76$} & \multirow{3}{*}{0.008} \\
\hline Occasionally & 11 & $15.63 \pm 10.55^{\star}$ & & \\
\hline Rarely & 15 & $12.97 \pm 4.88^{\star}$ & & \\
\hline \multicolumn{5}{|l|}{ Smoking Intensity } \\
\hline$<5$ sticks per day & 28 & $15.35 \pm 8.62$ & \multirow[t]{2}{*}{$\mathrm{t},-1.16$} & \multirow[t]{2}{*}{0.256} \\
\hline$\geq 5$ sticks per day & 2 & $22.54 \pm 3.03$ & & \\
\hline
\end{tabular}

*Significantly different from the reference variable ("always"). 
have lasted $\geq 5$ years. A similar result was observed between smokers who smoked $<5$ sticks/day and those who smoked $\geq 5$ sticks/day. In contrast, Bonferoni post-hoc test indicated significantly higher mean $\mathrm{COHb}$ level was found in subjects who smoked "always" (27.10\%) compared with those who smoked "occasionally" $(15.63 \% ; \mathrm{p}=0.04)$ and those who smoked "rarely" $(12.97 \% ; \mathrm{p}=0.006)$.

Table 5 shows the serum calcium levels of active smoking adults according to smoking duration, frequency, intensity and control of smoking habit. Data indicated lack of significant differences between subjects whose smoking habit have lasted for $<5$ years and those that have lasted $\geq 5$ years; among subjects who smoke "always", "occasionally" and "rarely"; between smokers who smoked $<5$ sticks/day and those who smoked $\geq 5$ sticks/day.

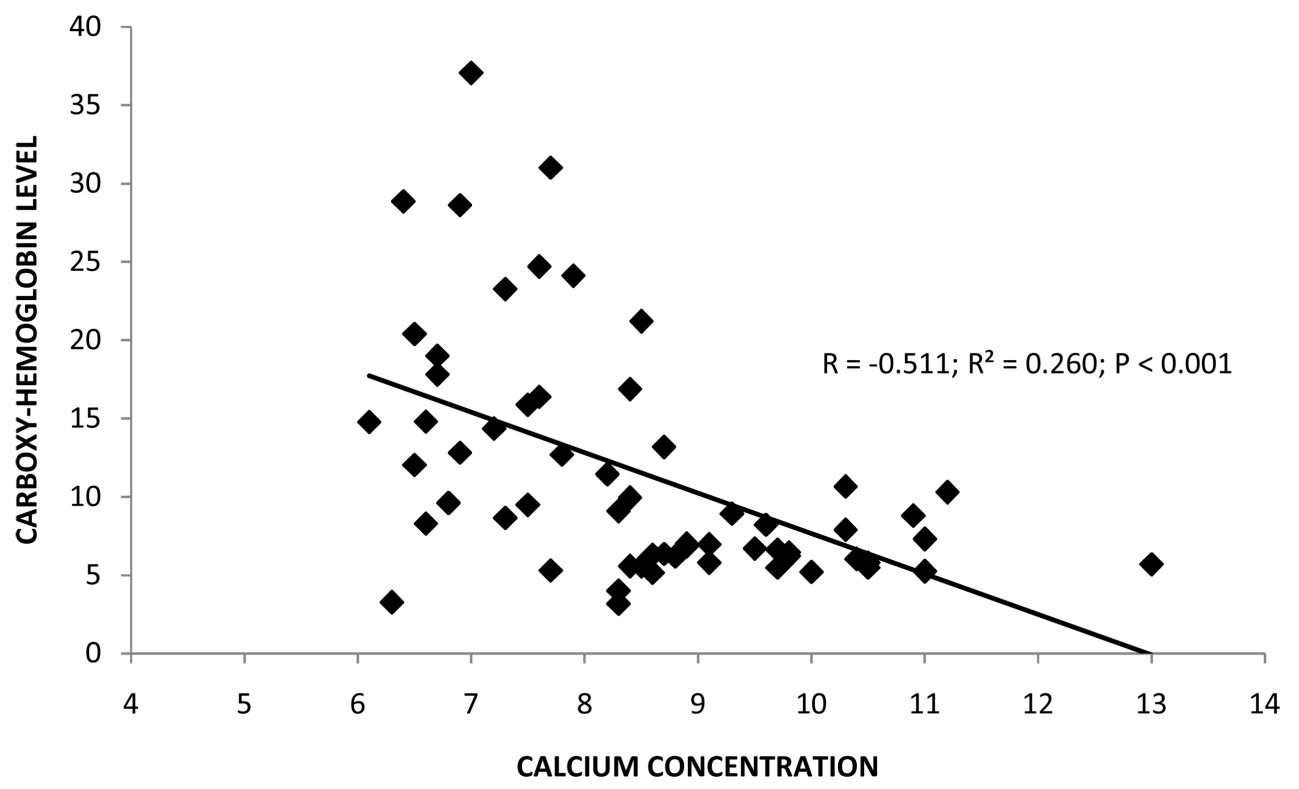

Figure 1. Scatterplot diagram showing the relationship between serum carboxyhemoglobin level and calcium concentration in the study population.

Table 5. Serum calcium levels of active smoking adults according to smoking duration, frequency and intensity.

\begin{tabular}{|c|c|c|c|c|}
\hline \multirow{2}{*}{ Characteristics } & \multirow{2}{*}{$\mathrm{N}$} & \multirow{2}{*}{$\begin{array}{c}\text { Calcium }(\mathrm{mg} / \mathrm{dl}) \\
\text { Mean } \pm \text { SD }\end{array}$} & \multicolumn{2}{|c|}{ Statistics } \\
\hline & & & Coefficient & P-Value \\
\hline \multicolumn{5}{|c|}{ Duration of Smoking Habit } \\
\hline$<5$ years & 21 & $7.24 \pm 0.74$ & $t,-0.846$ & 0.405 \\
\hline$\geq 5$ years & 9 & $7.50 \pm 0.76$ & & \\
\hline \multicolumn{5}{|l|}{ Frequency of Smoking } \\
\hline Always & 4 & $7.52 \pm 0.43$ & \multirow{3}{*}{ F, 0.166} & \multirow{3}{*}{0.848} \\
\hline Occasionally & 11 & $7.27 \pm 0.66$ & & \\
\hline Rarely & 15 & $7.30 \pm 0.88$ & & \\
\hline \multicolumn{5}{|l|}{ Smoking Intensity } \\
\hline$<5$ sticks per day & 28 & $7.34 \pm 0.75$ & $\mathrm{t}, 0.530$ & 0.600 \\
\hline$\geq 5$ sticks per day & 2 & $7.05 \pm 0.78$ & & \\
\hline
\end{tabular}




\section{DISCUSSION}

The present study indicated significantly higher mean $\mathrm{COHb}$ level among smokers compared with non-smokers. This finding confirms that smoking (particularly cigarette smoking) can result in high $\mathrm{COHb}$ levels [24, 25]. Incomplete combustion of inhaled tobacco and marijuana produces $\mathrm{CO}$ which has 200 to 250 times greater affinity for binding hemoglobin when compared to oxygen [26]. The resultant effect is an increase in blood $\mathrm{COHb}$ concentrations which may reach as high as $10 \%$ in normal tobacco smokers compared to $1 \%$ to $3 \%$ in nonsmokers [26]. The present finding is in agreement with previous studies which indicated higher $\mathrm{COHb}$ levels among smokers compared with non-smokers [27, 28]. We also observed that the mean $\mathrm{COHb}$ concentration among smokers $(15.83 \% \pm 8.53 \%)$ exceeded the reference value of $\leq 9 \%$ for smokers [29]. Similarly the non smokers indicated mean value $(7.19 \% \pm 2.65 \%)$ far above the normal healthy range of $1 \%-3 \%$ for non-smokers [26]. The reason for these increases in both the smokers and the non-smokers is the fact that a high level of $\mathrm{CO}$ is generated into the environment in Benin City and by extension Nigeria through different channels. These sources include smoke from automobile exhaust fumes, electricity generating sets, fire wood, kerosene stove, gas cookers and passive cigarette smoke. The act of public smoking combined with the already existing presence of carbon monoxide from other sources, constitutes a serious health challenge to smokers as well as to innocent, non smokers, who passively inhale the cigarette smoke.

The far higher level of $\mathrm{COHb}$ among smokers, further attests to the fact that smoke from cigarette has a significant influence on serum $\mathrm{COHb}$ level. Unfortunately, there is lack of effective government regulation and monitoring of laws controlling environmental pollution in Benin City and Nigeria generally. Furthermore, it appears there is both poor compliance and complete disregard to the laws prohibiting tobacco smoking in public by the smokers. This is because our result indicated a high level of awareness of the health risks of cigarette smoking among this group, who are constantly seen smoking publicly in motor parks in Benin City. It is noteworthy that high COHb levels above normal limits as observed in the present study may explain some of the symptoms associated with $\mathrm{CO}$ poisoning often seen among cigarette smokers, such as headache, dizziness, weakness, shortness of breath and muscle cramping.

There are limited data about the effect of cigarette smoking on the serum levels of calcium. In this study, the smokers indicated significantly lower mean calcium levels compared with the non smokers. This finding is in agreement with a previous study [30] which indicated a higher serum calcium level among Sudanese male cigarette smokers compared with the non-smoking control. It is not clear the mechanism behind the lower calcium level observed in smokers compared with non-smokers in this study. However, it is thought that the present result may be due to the interference of the activities of vitamin D by some of the chemical constituents of cigarette. The active form of vitamin D increases absorption of both calcium in the intestine and also increases its re-absorption, in the renal tubules hence, increasing the level of serum calcium in plasma [31]. Therefore, any interference with the action of vitamin D may lead to lowering of serum calcium. Studies have shown that cigarette smoke decreases the production of the active form of vitamin $\mathrm{D}(1,25$-dihydroxyvitamin $\mathrm{D})$ thus decreasing the absorption of vitamin $\mathrm{D}$ and calcium from the diet $[23,32]$. Another explanation is that smoking damages intestinal villi, which are a major component in digestion and absorption of nutrients [33]. The decreased ability to absorb calcium leading to decreased bone mineral density increases the risk of osteoporosis among smokers [33]. Interestingly, our study which indicated high level of $\mathrm{COHb}$, a resultant effect of exposure to one of the toxic chemical constituents of cigarette smoke (CO), also showed a significant negative correlation between $\mathrm{COHb}$ level and calcium concentration. These facts and findings may explain the lower calcium level observed in this study among smokers indicating the negative manifestation of cigarette smoke and its chemical components. We recommend the measurement of the 1,25-dihydroxyvitamin D levels among cigarette smokers in future studies, to help elucidate the present finding.

We further assessed whether the serum levels of $\mathrm{COHb}$ and calcium among smokers were influenced by smoking duration, frequency and intensity. We expected higher levels of $\mathrm{COHb}$ and lower levels of calcium in smokers that have been smoking longer than 5 years compared with those who have smoked for 
shorter duration. However, our result indicated no significant differences in both $\mathrm{COHb}$ and calcium levels between smoker with regard to smoking duration ( $<5$ years vs. $\geq 5$ years). These findings suggest that the duration of smoking habit has no significant influence on serum levels of $\mathrm{COHb}$ and calcium. A previous study [34] has also indicated that $\mathrm{COHb}$ did not differ between those who smoked less than 10 years and those who have been smoking for more than 10 years.

The smoking frequency affected the level of $\mathrm{COHb}$, but not the calcium level. Significantly higher level of $\mathrm{COHb}$ was found in subjects who smoked "always" compared with those who smoked "occasionally" and those who smoked. This suggests that the $\mathrm{COHb}$ level may be influenced by the number of times the smoker is exposed to cigarette smoke or other CO producing sources in a given period of time. This in agreement with a previous observation by Sokal and Kralkowska that the severity of CO poisoning depends more on the frequency of exposure than on the inhaled CO levels [35].

Although higher mean value of $\mathrm{COHb}$ was observed in smokers who consumed $\geq 5$ sticks of cigarette per day (22.54\%) compared with those who smoked less than 5 sticks per day (15.35\%), no statistical difference was found between the two groups. This may be attributed to small sample size of those smoked greater than five sticks of cigarette $(\mathrm{n}=2)$. It is well established that there is a dose-dependent increase in $\mathrm{COHb}$ concentration with tobacco smoke, and with the heavy smokers showing $\mathrm{COHb}$ levels $<10 \%$ to $15 \%$ [36]. A previous study among British men also indicated a strong dose response relationship between number of cigarettes smoked and $\mathrm{COHb}$ level up to 20 cigarettes per day [2]. It is also note worthy that calcium level was not influenced by the number of cigarette sticks consumed by the smokers.

\section{CONCLUSION}

The present study indicated significantly higher serum $\mathrm{COHb}$ and lower calcium levels among male smokers compared with non-smokers. The mean $\mathrm{COHb}$ level also exceeded the reference value for smokers. Our result therefore confirms that cigarette smoking contributes to abnormally high COHb levels, which is associated with adverse health consequences from carbon-monoxide poisoning in the body. It is also believed that the toxic chemicals in cigarette smoke (CO inclusive) may have interfered with the mechanisms responsible for the absorption of calcium in the gastro-intestinal tract of smokers, thus leading to poor absorption as well as low levels of calcium in their blood. Furthermore, higher COHb level in non-smoking residents living in the urban centers suggests that this part of general population can also be at risk of developing symptoms of $\mathrm{CO}$ poisoning arising from passive smoking and other sources of $\mathrm{CO}$ abundant in Nigerian urban environments. Furthermore, the $\mathrm{COHb}$ levels among smokers were influenced by smoking frequency, but not by duration of smoking habit or number of sticks consumed per day. On the other hand, the smokers' serum calcium level was not affected by smoking duration, frequency and intensity.

\section{CONFLICTS OF INTEREST}

The authors declare no conflicts of interest regarding the publication of this paper.

\section{REFERENCES}

1. Bol, O., Koyuncu, S. and Günay, N. (2018) Prevalence of Hidden Carbon Monoxide Poisoning in Autoservice Workers; a Prospective Cohort Study. Journal of Occupational Medicine and Toxicology, 13, 35. https://doi.org/10.1186/s12995-018-0214-9

2. Whincup, P., Papacosta, O., Lennon, L. and Haines, A. (2006) Carboxyhaemoglobin Levels and Their Determinants in Older British Men. BMC Public Health, 6, Article No. 189. https://doi.org/10.1186/1471-2458-6-189

3. Townsend, C.L. and Maynard, R.L. (2002) Effects on Health of Prolonged Exposure to Low Concentrations of Carbon Monoxide. Occupational and Environmental Medicine, 59, 708-711. https://doi.org/10.1136/oem.59.10.708

4. World Health Organization (1999) Environmental Health Criteria 213: Carbon Monoxide. Report. 
5. Kleinman, M.T., Davidson, D.M., Vandagriff, R.B., Caiozzo, V.J. and Whittenberger, J.L. (1989) Effects of Short-Term Exposure to Carbon Monoxide in Subjects with Coronary Artery Disease. Archives of Environmental Health, 44, 361-369. https://doi.org/10.1080/00039896.1989.9935908

6. Allred, E.N., Bleecker, E.R., Chaitman, B.R., Dahms, T.E., Gottlieb, S.O., Hackney, J.D., Pagano, M., Selvester, R.H., Walden, S.M. and Warren, J. (1989) Short-Term Effects of Carbon Monoxide Exposure on the Exercise Performance of Subjects with Coronary Artery Disease. The New England Journal of Medicine, 321, 1426-1432. https://doi.org/10.1056/NEJM198911233212102

7. Aronow, W.S. and Cassidy, J. (1975) Effect of Carbon Monoxide on Maximal Treadmill Exercise. A Study in Normal Persons. Annals of Internal Medicine, 83, 496-499. https://doi.org/10.7326/0003-4819-83-4-496

8. Morris, R.D., Naumova, E.N. and Munasinghe, R.L. (1995) Ambient Air Pollution and Hospitalization for Congestive Heart Failure among Elderly People in Seven Large US Cities. American Journal of Public Health, 85, 1361-1365. https://doi.org/10.2105/AJPH.85.10.1361

9. Burnett, R.T., Dales, R.E., Brook, J.R., Raizenne, M.E. and Krewski, D. (1997) Association between Ambient Carbon Monoxide Levels and Hospitalizations for Congestive Heart Failure in the Elderly in 10 Canadian Cities. Epidemiology, 8, 162-167. https://doi.org/10.1097/00001648-199703000-00007

10. Wald, N., Howard, S., Smith, P.G. and Kjeldsen, K. (1973) Association between Atherosclerotic Diseases and Carboxyhaemoglobin Levels in Tobacco Smokers. British Medical Journal, 1, 761-765.

https://doi.org/10.1136/bmj.1.5856.761

11. Borland, C., Chamberlain, A., Higenbottam, T., Shipley, M. and Rose, G. (1983) Carbon Monoxide Yield of Cigarettes and Its Relation to Cardiorespiratory Disease. British Medical Journal, 287, 1583-1586.

https://doi.org/10.1136/bmj.287.6405.1583

12. Linus Pauling Institute (2021) Calcium. Oregon State University, Corvallis. https://lpi.oregonstate.edu/mic/minerals/calcium

13. US National Institutes of Health (2019) Calcium: Fact Sheet for Health Professionals. Office of Dietary Supplements, US National Institutes of Health, Bethesda.

14. Cooper, M.S. and Gittoes, N.J. (2008) Diagnosis and Management of Hypocalcaemia. BMJ, 336, 1298-1302. https://doi.org/10.1136/bmj.39582.589433.BE

15. Hluchan, S.E. and Pomerantz, K. (2006) Calcium and Calcium Alloys. Willy Online Library, 489-494. https://doi.org/10.1002/14356007.a04 515.pub2

16. Murphy, E. and Williams, G.R. (2009) Hypocalcaemia. Medicine, 37, 465-468. https://doi.org/10.1016/j.mpmed.2009.06.003

17. U.S. Department of Health and Human Services (2010) How Tobacco Smoke Causes Disease: What It Means to You. U.S. Department of Health and Human Services, Centers for Disease Control and Prevention, National Center for Chronic Disease Prevention and Health Promotion, Office on Smoking and Health, Atlanta.

18. USDHHS (2010) Ending the Tobacco Epidemic: A Tobacco Control Strategic Action Plan for the US Department of Health and Human Services. Office of the Assistant Secretary for Health, Washington DC.

19. USDHHS (2012) Preventing Tobacco Use among Youth and Young Adults: A Report of the Surgeon General. Vol. 3, US Department of Health and Human Services, Centers for Disease Control and Prevention, National Center for Chronic Disease Prevention and Health Promotion, Office on Smoking and Health, Atlanta.

20. Corwin, E.J., Klein, L.C. and Rickelman, K. (2002) Predictors of Fatigue in Healthy Young Adults: Moderating Effects of Cigarette Smoking and Gender. Biological Research in Nursing, 3, 223-233. https://doi.org/10.1177/109980040200300407

21. Furlanetto, K.C., Mantoani, L.C., Bisca, G., Morita, A.A., Zabatiero, J., Proença, M., Kovelis, D. and Pitta, F. 
(2014) Reduction of Physical Activity in Daily Life and Its Determinants in Smokers without Airflow Obstruction. Respirology, 19, 369-375. https://doi.org/10.1111/resp.12236

22. HHS (Department of Health and Human Services) (2010) How Tobacco Smoke Causes Disease: The Biology and Behavioral Basis for Smoking-Attributable Disease: A Report of the Surgeon General. U.S. Department of Health and Human Services, Centers for Disease Control and Prevention, National Center for Chronic Disease Prevention and Health Promotion, Office on Smoking and Health, Atlanta.

23. Cusano, N.E. (2015) Skeletal Effects of Smoking. Current Osteoporosis Reports, 13, 302-309. https://doi.org/10.1007/s11914-015-0278-8

24. Institute for Environment and Health (1998) IEH Assessment on Indoor Air Quality in the Home: Carbon Monoxide. Report, Institute for Environment and Health, Leicester.

25. Radford, E.P. and Drizd, T.A. (1982) Blood Carbon Monoxide Levels in Persons 3 - 74 Years of Age: United States, 1976-80. Advance Data, Vol. 76, National Center for Health Statistics, U.S. Department of Health and Human Services, Washington DC, 1-24.

26. Ernst, A. and Zibrak, J.D. (1998) Carbon Monoxide Poisoning. The New England Journal of Medicine, 339, 1603-1608. https://doi.org/10.1056/NEJM199811263392206

27. Light, A., Grass, C., Pursley, D. and Krause, J. (2007) Carboxyhemoglobin Levels in Smokers vs. Non-Smokers in a Smoking Environment. Respiratory Care, 52, 1576.

28. Goel, A., Deepak, D. and Gaur, N. (2010) Study of Relationship of Tobacco Smoking with Haemoglobin Concentration in Healthy Adults. Journal of Pharmaceutical and Biomedical Sciences, 1, 1-3.

29. Centers for Disease Control and Prevention (2014) Clinical Guidance for Carbon Monoxide (CO) Poisoning after a Disaster. http://emergency.cdc.gov/disasters/co_guidance.asp

30. Hussein, S.E.O. (2015) Effect of Cigarettes Smoking on the Serum Levels of Calcium and Phosphate in Sudanese Males in Khartoum. International Journal of Research in Pharmacy and Biosciences, 2, 4-9.

31. Baron, J.A., Comi, R.J., Cryns, V., Brinck, J.T. and Mercer, N.G. (2005) The Effect of Cigarette Smoking on Adreral Cortical Hormones. Journal of Pharmacology and Experimental Therapeutics, 272, 151-155.

32. Hansdottir, S., Monick, M.M., Lovan, N., Powers, L.S. and Hunninghake, G.W. (2010) Smoking Disrupts Vitamin D Metabolism in the Lungs [Abstract]. American Journal of Respiratory and Critical Care Medicine, 181, A1425. https://doi.org/10.1164/ajrccm-conference.2010.181.1 MeetingAbstracts.A1425

33. Krall, E.A. and Hughes, B.D. (1999) Smoking Increases Bone Loss and Decreases Intestinal Calcium Absorption. Journal of Bone Mineral Research, 14, 215-220. https://doi.org/10.1359/jbmr.1999.14.2.215

34. Buha, A., Vaseashta, A., Bulat, Z. and Matovic, V. (2013) Carboxyhemoglobin in Blood of Smokers and Non-Smokers Determined by Gas Chromatography with Thermal Conductivity Detector. In: Advanced Sensors for Safety and Security, NATO Science for Peace and Security Series B: Physics and Biophysics, Springer, Berlin, 161-168. https://doi.org/10.1007/978-94-007-7003-4 13

35. Sokal, J.A. and Kralkowska, E. (1985) The Relationship between Exposure Duration, Carboxyhemoglobin, Blood Glucose, Pyruvate and Lactate and the Severity of Intoxication in 39 Cases of Acute Carbon Monoxide Poisoning in Man. Archives of Toxicology, 57, 196-199. https://doi.org/10.1007/BF00290887

36. Sen, S., Peltz, C., Beard, J. and Zeno, B. (2010) Recurrent Carbon Monoxide Poisoning from Cigarette Smoking. The American Journal of the Medical Sciences, 340, 427-428. https://doi.org/10.1097/MAJ.0b013e3181ef712d 